\title{
Prolonged Oxygen Kinetics During Constant Workload Submaximal Exercise Is Associated With Disease Severity in Adult Subjects With Cystic Fibrosis
}

\author{
Eleni Armeniakou MD, Georgia Perpati MD, Stavros Dimopoulos MD, Petros Roditis MD, \\ Maria Avdikou MD, Nikolaos Barouchos MD, Vasiliki Dionisopoulou MD, and \\ Serafim Nanas MD
}

\begin{abstract}
BACKGROUND: The goal of this study was to explore the relation between oxygen kinetics during constant work load submaximal cardiopulmonary exercise test (CPET) and disease severity in adult subjects with cystic fibrosis. METHODS: Fourteen adult subjects with cystic fibrosis (CF; 8 males, $22 \pm 4 \mathrm{y}$ old $)$ and a mean Schwachman score of $73 \pm 11$ and 10 healthy individuals (5 males, $29 \pm 4$ y old) underwent pulmonary function tests at rest, maximal and constant work load submaximal CPET on a cycloergometer. Breath-by-breath analysis was used for measuring oxygen kinetic parameters and the time constant (tau), expressing phase 2 of submaximal CPET. RESULTS: Subjects with CF had a significantly prolonged tau compared with healthy subjects $(42.3 \pm 21.5$ vs $29.3 \pm 6.4, \mathrm{~s}, P<.05)$. The tau during phase 2 was inversely correlated with $\mathrm{FEV}_{1}(\%$ pred $)$ $(\mathrm{r}=-0.77, P=.001)$, breathing reserve $(\mathrm{r}=-0.74, P=.003), \dot{\mathrm{V}}_{\text {O2peak }}(\mathrm{r}=-0.53, P=.049), \dot{\mathrm{V}}_{\mathrm{O} 2} / \mathrm{t}$ slope $(\mathrm{r}=-0.58, P=.03)$, and Schwachman score $(\mathrm{r}=-0.80, P=.001)$. In a multivariate regression model including all the above variables, the Schwachman score $(\beta=-0.697, P=.002)$ emerged as independent predictor of tau $\left(R^{2}=0.719, P=.001\right)$. CONCLUSIONS: We conclude that adult subjects with $C F$ present significant prolonged oxygen kinetics during constant work load submaximal exercise in relation to disease severity. Thus, submaximal exercise should be considered the preferable CPET choice in adult patients with severe CF. Key words: cystic fibrosis; submaximal exercise; time constant (tau). [Respir Care 2015;60(8):1164-1171. (C) 2015 Daedalus Enterprises]
\end{abstract}

\section{Introduction}

Cystic fibrosis (CF) is a progressive, life-limiting disease, with an incidence of 1:2,000 to 1:3,500 among white

\footnotetext{
Drs Armeniakou, Perpati, Avdikou, Barouchos, and Dionisopoulou are affiliated with the 10th Pulmonary Department, Athens Chest Hospital, Athens, Greece. Drs Dimopoulos, Roditis, and Nanas are affiliated with the 1st Critical Care Medicine Department, Cardiopulmonary Exercise Testing and Rehabilitation Laboratory, Evgenidio Hospital, National and Kapodistrian University of Athens, Athens, Greece.
}

The authors have disclosed no conflicts of interest.

Correspondence: Serafim Nanas MD, 1st Critical Care Medicine Department, Evgenidio Hospital, National and Kapodistrian University of Athens, Papadiamantopoulou Street, Athens 11528, Greece. E-mail: a.icusn@gmail.com.

DOI: $10.4187 /$ respcare. 03258 populations. ${ }^{1}$ It is caused by mutations in a single gene on the long arm of chromosome 7, which encodes a protein, the cystic fibrosis transmembrane conductance regulator (CFTR). ${ }^{2}$ More than 1,500 mutations have been identified to be responsible for CFTR quantity or quality defects leading to abnormal chloride concentration across the apical membrane of epithelial cells, especially in the airways and pancreas. This results in thick secretions and, through a vicious cycle of inflammation and infection, in progressive lung disease and malnutrition. ${ }^{2}$ The disease most commonly affects the respiratory system among the adult population, increasing morbidity and determining the patients' survival. ${ }^{3,4}$

The prognosis of the disease is worse in women, and it is dependent on nutritional status, respiratory involvement, colonization by Pseudomonas aeruginosa, and existence of complications such as pneumothorax and right ventricular failure. ${ }^{5}$ Advances in the diagnosis 
and the therapeutic management of CF have gradually led to a significant increase in life expectancy, accompanied by a corresponding increase in the survival rate of CF patients. ${ }^{6}$

Lung function parameters such as $\mathrm{FEV}_{1},{ }^{7}$ peak oxygen uptake $\left(\dot{\mathrm{V}}_{\mathrm{O}_{2 \text { peak }}}\right)$ during incremental cardiopulmonary exercise testing (CPET) ${ }^{8}$ and the clinical evaluation system known as the Schwachman score ${ }^{9}$ are common prognostic indices used to assess functional capacity and disease severity in $\mathrm{CF}$ patients. Peak exercise capacity is reduced in $\mathrm{CF},{ }^{10}$ and the main responsible factors are diminished pulmonary and nutritional status, ${ }^{11}$ as well as peripheral muscle weakness. ${ }^{12}$ Although maximal CPET is a useful clinical tool to measure aerobic capacity directly, it remains difficult for debilitated patients to perform this test, especially CF patients. An alternative modality for estimating aerobic capacity could be oxygen kinetics during submaximal constant work load exercise testing. However, there are very limited data concerning constant work load oxygen kinetics in subjects with CF. ${ }^{13}$ These data consist mainly of lung function decline and oxygen desaturation during 6-min walk test in children and patients who have received transplants. Furthermore, oxygen kinetics during exercise has been correlated with disease severity only during maximal CPET.

In this study, we hypothesized that (1) adult subjects with CF present impaired oxygen kinetics during constant work load submaximal CPET, and (2) oxygen kinetics is related to disease severity in CF. The aim of this study was to explore oxygen kinetics during constant work load submaximal CPET in adult subjects with cystic fibrosis in comparison with healthy subjects and in relation to disease severity.

\section{Methods}

This study involved 14 adult subjects with CF (8 males, mean age: $22 \pm 4$ y old) referred to the CF out-patient clinic of our Institute and 10 healthy individuals (controls) (5 males, mean age: $29 \pm 4$ y old). The diagnosis of CF was based on clinical evaluation and laboratory testing, including sweat testing and genotype analysis. All participants were physically active, nonsmokers, and not engaged in regular training. All subjects were clinically stable and optimally treated at the time of the study. Subjects had no clinical symptomatology or signs of cardiac disease, and there was no history of any cardiovascular risk factor for ischemic heart disease. All subjects with CF before referral to our CF out-patient clinic had a routine echocardiogram, which had shown cardiac function within normal limits. Patients and healthy subjects with history of recently (within the previous month) diagnosed pulmonary infection or respiratory failure, cardiac, orthopedic, or neurological problems affecting exercise capacity were ex-

\section{QUICK LOOK}

\section{Current knowledge}

Lung function parameters such as $\mathrm{FEV}_{1}$ and peak oxygen uptake during incremental cardiopulmonary exercise testing are common prognostic indices used to assess functional capacity and disease severity in cystic fibrosis patients. However, patients with severe disability cannot always tolerate maximal exercise. An alternative modality for estimating aerobic capacity could be oxygen kinetics during submaximal constant workload exercise testing.

\section{What this paper contributes to our knowledge}

Adult subjects with cystic fibrosis demonstrated significant prolonged oxygen kinetics during constant workload submaximal exercise in relation to disease severity. These data suggest that submaximal exercise should be considered as the preferable choice for cardiopulmonary exercise testing in adult subjects with severe cystic fibrosis.

cluded from the study. None of the controls suffered from any acute or chronic disease at the time of testing, or were under medication. The institutional review board approved the study, informed consent was obtained from all subjects, and the study was conducted in accordance with applicable laws and regulations, including the International Conference on Harmonization Guideline for Good Clinical Practice (http://www.ich.org. Accessed January 26, 2015.).

\section{Design of the Study}

All subjects with $\mathrm{CF}$ and healthy subjects underwent a spirometric evaluation, a symptom-limited CPET, and a constant work load CPET. Subjects with CF were also clinically assessed, and the Schwachman score was calculated.

The latter is a scoring system based on 4 separate aspects of the disease profile: (1) general activity, (2) physical findings (degree of clubbing, auscultatory findings, cough, and sputum), (3) nutritional status, and (4) chest $\mathrm{x}$-ray findings. Each item is given equal weight, from 0 to 25 points. A total of 86 points represents a perfect score, ${ }^{9}$ whereas a total below 40 points represents a severe condition. The Schwachman score is calculated by 2 different observers to obtain objective results.

\section{Pulmonary Function Assessment}

Study participants (healthy and CF subjects) underwent measurement of $\mathrm{FVC}$ and $\mathrm{FEV}_{1}$ in the sitting position with 
a closed-circuit spirometer (Sensormedics, Yorba Linda, California) as recommended by the American Thoracic Society ${ }^{14}$ In addition, participants underwent inspiratory capacity (IC) measurement in the sitting position, before exercise, according to previous studies. ${ }^{15,16}$

\section{CPET}

Subjects underwent a symptom-limited, incremental CPET on a cycloergometer (model 2000, Marquette Electronics, Milwaukee, Wisconsin) in a sitting position. Cardiopulmonary data were recorded for $2 \mathrm{~min}$ at rest followed by $3 \mathrm{~min}$ of unloaded pedaling. The work rate increment was estimated by using the equation of Hansen et $\mathrm{al}^{17}$ to attain test duration of $8-12 \mathrm{~min}$. A 12-lead electrocardiogram was recorded every minute using the Max 1 system (Marquette Electronics). Blood pressure measurements were made with a standard mercury sphygmomanometer and IC maneuvers were performed every $2 \mathrm{~min}$ during exercise and at peak exercise. The IC maneuvers were first explained and then practiced by the subjects until reproducible efforts were made, as previously described $^{15,16}$ and IC peak was measured at the end of exercise. We also measured breathing reserve at maximal exercise as: (MVV - peak VE)/MVV, where MVV was the maximal voluntary ventilation obtained from $40 \times \mathrm{FEV}_{1}$. A pulse oximeter was used for $\mathrm{S}_{\mathrm{pO}_{2}}$ monitoring. The subjects breathed through a mouthpiece with a nose clip in place. Oxygen uptake $\left(\dot{\mathrm{V}}_{\mathrm{O}_{2}}\right)$, carbon dioxide output $\left(\dot{\mathrm{V}}_{\mathrm{CO}_{2}}\right)$, and air flow were measured on a breathby-breath basis using the Vmax 229 monitor for pulmonary and metabolic studies (Sensormedics). The system was calibrated with a gas mixture of known concentration before each test. Measurements were obtained in the sitting position before and during exercise. Baseline $\dot{\mathrm{V}}_{\mathrm{O}_{2}}$ was calculated by averaging the measurements made for 2 min before the beginning of exercise. $\dot{\mathrm{V}}_{\mathrm{O}_{2 \text { peak }}}$ was calculated as the average of measurements made during the last $20 \mathrm{~s}$ of incremental exercise testing. Anaerobic threshold (AT) was determined using the $\mathrm{V}$-slope technique, ${ }^{18}$ and the result confirmed by a graph on which the respiratory equivalent for oxygen $\left(\dot{\mathrm{V}}_{\mathrm{E}} / \dot{\mathrm{V}}_{\mathrm{O}_{2}}\right)$ and carbon dioxide $\left(\dot{\mathrm{V}}_{\mathrm{E}} / \dot{\mathrm{V}}_{\mathrm{CO}_{2}}\right)$ were plotted simultaneously against time. Heart rate and oxygen pulse $\left(\mathrm{O}_{2}\right.$ pulse: $\dot{\mathrm{V}}_{\mathrm{O}_{2}}$ /heart rate) at peak exercise were also calculated.

To evaluate the oxygen uptake kinetics during early recovery, the first degree slope of $\dot{\mathrm{V}}_{\mathrm{O}_{2}}$ for the first $1 \mathrm{~min}$ of recovery period ${ }^{10,19}$ was calculated by linear regression using an appropriate computerized statistical program, assuming that the fall in $\dot{\mathrm{V}}_{\mathrm{O}_{2}}$ during early recovery is linear. The ventilatory response to exercise was calculated as the slope by linear regression of $\mathrm{V}_{\mathrm{E}}$ versus $\dot{\mathrm{V}}_{\mathrm{CO}_{2}}$ from the beginning of exercise to AT as in previous studies. ${ }^{10,15,18,20}$ Peak work rate was defined as the highest work level reached and maintained at a pedaling frequency of no less than $50 \mathrm{rpm}$ for $20 \mathrm{~s}$. Subjects were instructed to exercise until exhaustion. A respiratory exchange ratio $>1.09$ was considered to be an indication of a nearly maximal effort.

\section{Constant Work Load Submaximal CPET}

After $1 \mathrm{~h}$ of rest, each study participant underwent a constant load exercise test in a cycloergometer. Initially, the test load was set at $80 \%$ of the value of the work rate (WR) corresponding to the AT detected in the maximum test, which was performed first (with a minimum value of $30 \mathrm{~W}) .{ }^{20,21}$

Cardiopulmonary data were recorded for 2 min at rest, followed by 3 min of unloaded pedaling. After unloaded pedaling, subjects performed the constant load test for $7 \mathrm{~min}$ at the work load rate described above, followed by unloaded pedaling for $5 \mathrm{~min}$. We used a 7-min work load for a better evaluation of all oxygen kinetics phases. To improve the confidence of the kinetic parameter determination, ${ }^{22}$ this test was performed 3 times, and the averaged profile was used for the kinetics analysis. We also chose to limit the constant work rate to the sub-anaerobic threshold range to obviate the confounding influence of the slow component of the kinetics at work rates associated with a sustained increase in lactate levels. ${ }^{23}$ The breath-by-breath measurements of each curve were edited only for breaths that were not reflective of the underlying physiological process $^{22,23}$ interpolated to a second-by-second basis, timealigned, and averaged to produce a single response. Curve fitting was performed with Origin 7.0 graphics software (Microcal Software, Northampton, Massachusetts) using iterative techniques. ${ }^{20}$

$\dot{\mathrm{V}}_{\mathrm{O}_{2}}$ response was described by a 3-phase model. ${ }^{20,21}$ To characterize phase 1 (cardiodynamic phase), we used the period from the start of the exercise to the point when the respiratory exchange ratio started to fall in conjunction with end-tidal $\mathrm{P}_{\mathrm{O}_{2}}$ starting to fall and end-tidal $\mathrm{P}_{\mathrm{CO}_{2}}$ starting to increase. During phase $2, \dot{\mathrm{V}}_{\mathrm{O}_{2}}$ continues to increase as its consumption by muscles increases, and it is defined as the exponential period beginning immediately following phase 1 , until steady state (phase 3 ) at moderate WR levels. The exponential curve of phase 2 is described by the equation: $\Delta \mathrm{y}(\mathrm{t})=\mathrm{A}\left[1-\mathrm{e}^{-(\mathrm{t}-\mathrm{TD}) / \tau)}\right]$, which provides estimates of the time constant (tau). The dependent variable $\Delta y(t)$ equals the increase in oxygen uptake at time $t$, A equals the increase in oxygen uptake from the onset of loaded exercise to steady-state exercise (phase 3), and TD is the time delay from the onset of loaded exercise until the beginning of the exponential rise in oxygen uptake. There is theoretical and experimental evidence to analyze $\dot{\mathrm{V}}_{\mathrm{O}_{2}}$ responses of submaximal CPET by separating phase 1 and 
Slowed Oxygen Kinetics in Cystic Fibrosis

Table 1. Baseline Demographic Characteristics and Pulmonary Function Assessment at Rest in Subjects With Cystic Fibrosis and Controls

\begin{tabular}{|c|c|c|c|}
\hline & $\begin{array}{l}\text { Subjects } \\
(n=14)\end{array}$ & $\begin{array}{l}\text { Controls } \\
(n=10) \\
\end{array}$ & $P$ \\
\hline Gender (males) & 8 & 5 & \\
\hline Age (y) & $22 \pm 4$ & $29 \pm 4$ & .003 \\
\hline BMI $\left(\mathrm{kg} / \mathrm{m}^{2}\right)$ & $21.6 \pm 3.2$ & $23.1 \pm 2.9$ & .24 \\
\hline Schwachman score & $73 \pm 11$ & NA & NA \\
\hline $\mathrm{FEV}_{1}(\%$ pred $)$ & $76.7 \pm 31.6$ & $105.9 \pm 14.9$ & .007 \\
\hline FVC (\% pred) & $89.2 \pm 29.7$ & $106.9 \pm 14.3$ & .07 \\
\hline $\mathrm{FEV}_{1} / \mathrm{FVC}(\%)$ & $72.9 \pm 11.6$ & $86.5 \pm 5.6$ & .001 \\
\hline IC at baseline (L) & $2.6 \pm 0.8$ & $2.8 \pm 0.6$ & .18 \\
\hline $\begin{array}{l}\text { Continuous variables are } \mathrm{p} \\
\mathrm{BMI}=\text { body mass index } \\
\mathrm{NA}=\text { not applicable } \\
\% \text { pred = percentage of pr } \\
\mathrm{IC}=\text { inspiratory capacity }\end{array}$ & as mean $\pm \mathrm{SD}$. & & \\
\hline
\end{tabular}

phase $2,,^{20,21,24}$ as phase 1 is the cardiodynamic phase and expresses the abrupt increase in oxygen consumption, whereas the phase 2 expresses mainly the oxygen consumption by muscles.

\section{Statistical Analysis}

All continuous variables are presented as mean $\pm \mathrm{SD}$. All variables were tested for normal distribution. The unpaired Student $t$ test was used to compare group means of continuous variables of subjects with $\mathrm{CF}$ and healthy subjects. The Pearson correlation coefficient was used to test correlations. A univariate linear regression was performed to examine which variables were associated with tau. A multivariate linear regression analysis was then performed to examine which variables were associated independently with tau. A $P$ value $<0.05$ was considered as statistically significant.

\section{Results}

Anthropometric, clinical, and resting pulmonary function characteristics of both groups are listed in Table 1.

Spirometric evaluation in subjects with CF showed a mild obstructive pattern compared with healthy subjects with significantly reduced $\mathrm{FEV}_{1}$ and $\mathrm{FEV}_{1} / \mathrm{FVC}$ (Table 1 ), but without any statistically significant difference in IC between the 2 groups. Subjects with CF were significantly younger compared with healthy subjects (Table 1).

Table 2 summarizes the cardiorespiratory and metabolic exercise response of subjects with CF and healthy subjects during symptom-limited and constant work load submaxi-
Table 2. Maximal and Submaximal Cardiopulmonary Exercise Testing Parameters in Subjects With Cystic Fibrosis and Controls

\begin{tabular}{lccc}
\hline \hline & $\begin{array}{c}\text { Subjects } \\
(n=14)\end{array}$ & $\begin{array}{c}\text { Controls } \\
(n=10)\end{array}$ & $P$ \\
\hline Maximal CPET parameters & & & \\
$\dot{\mathrm{V}}_{\mathrm{O}_{2 \text { peak }}}(\mathrm{L} / \mathrm{min})$ & $1.6 \pm 0.4$ & $2.1 \pm 0.4$ & .009 \\
$\dot{\mathrm{V}}_{\mathrm{O}_{2 \text { peak }}}(\mathrm{mL} / \mathrm{kg} / \mathrm{min})$ & $26.4 \pm 6.9$ & $35.4 \pm 7.7$ & .007 \\
$\mathrm{AT}(\mathrm{mL} / \mathrm{kg} / \mathrm{min})$ & $15.2 \pm 4.7$ & $25.6 \pm 4.8$ & $<.001$ \\
$\dot{\mathrm{V}}_{\mathrm{O}_{2}} / \mathrm{t}$ slope $\left(\mathrm{L} / \mathrm{min}^{2}\right)$ & $0.74 \pm 0.28$ & $0.95 \pm 0.19$ & .048 \\
$\mathrm{~V}_{\mathrm{E}} / \mathrm{V}_{\mathrm{CO}_{2}}$ slope & $30 \pm 5$ & $26 \pm 3$ & .046 \\
$\mathrm{O}_{2}$ pulse $(\mathrm{mL} / \mathrm{beat})$ & $9.6 \pm 2.4$ & $12.5 \pm 2.7$ & .01 \\
$\mathrm{HR}_{\text {peak }}($ beats/min$)$ & $171 \pm 12$ & $175 \pm 25$ & .15 \\
$\mathrm{IC}_{\text {peak }}(\mathrm{L})$ & $2.5 \pm 0.7$ & $2.7 \pm 0.6$ & .27 \\
$\mathrm{BR}(\%)$ & $19 \pm 28$ & $19 \pm 3$ & .96 \\
$\mathrm{WR}_{\text {peak }}$ (watts) & $139 \pm 35$ & $150 \pm 29$ & .45 \\
Submaximal CPET parameters & & & \\
Phase I $(\mathrm{t}, \mathrm{s})$ & $29.4 \pm 10.2$ & $23.5 \pm 6.3$ & .10 \\
Phase II (tau, s) & $42.3 \pm 21.5$ & $29.3 \pm 6.4$ & .049 \\
& & &
\end{tabular}

Continuous variables are presented as mean $\pm \mathrm{SD}$

$\mathrm{CPET}=$ cardiopulmonary exercise testing parameter

$\dot{\mathrm{V}}_{\mathrm{O}_{2 \text { peak }}}=$ peak oxygen uptake

$\mathrm{AT}=$ anaerobic threshold

$\dot{\mathrm{V}}_{\mathrm{O}_{2}} / \mathrm{t}$ slope $=$ first-degree slope of $\dot{\mathrm{V}}_{\mathrm{O}_{2}}$ for the first $1 \mathrm{~min}$ of recovery

$\dot{\mathrm{V}}_{\mathrm{E}} / \mathrm{V}_{\mathrm{CO}_{2}}$ slope $=$ slope of the ventilatory equivalent for carbon dioxide output

$\mathrm{HR}_{\text {peak }}=$ heart rate at peak of maximal exercise

$\mathrm{IC}_{\text {peak }}=$ inspiratory capacity at peak of maximal exercise

$\mathrm{BR}=$ breathing reserve

$\mathrm{WR}_{\text {peak }}=$ peak work rate

$\mathrm{t}=$ mean duration of phase I of submaximal CPET

tau $=$ time constant of phase II during submaximal CPET

mal CPET. There were no electrocardiogram findings indicating ischemia during symptom-limited CPET in either the $\mathrm{CF}$ or control group.

Exercise capacity was significantly reduced in subjects with $\mathrm{CF}$ compared with healthy subjects as assessed by $\dot{\mathrm{V}}_{\mathrm{O}_{2 \text { peak }}}$ and AT, whereas there was a significantly decreased $\mathrm{O}_{2}$ pulse and an increased $\dot{\mathrm{V}}_{\mathrm{E}} / \dot{\mathrm{V}}_{\mathrm{CO}_{2}}$ slope. In the group of subjects with $\mathrm{CF}$, there was significant prolonged oxygen recovery kinetics as expressed by $\dot{\mathrm{V}}_{\mathrm{O}_{2}}$ /t slope compared with healthy subjects.

Subjects with CF had also a significantly increased duration of phase $2 \dot{\mathrm{V}}_{\mathrm{O}_{2}}$ response during submaximal CPET as compared with healthy subjects $(42.3 \pm 21.5$ vs $29.3 \pm 6.4, \mathrm{~s}, P=.05$ ) (Fig. 1). Phase 1 duration was prolonged in subjects with CF compared to healthy subjects; however, there was no statistically significant difference between the 2 groups.

A statistically significant negative correlation between FEV (pred), FVC(pred), $\mathrm{FEV}_{1} / \mathrm{FVC}$, and tau was found ([r $=-0.77, P=.001$, Fig. 2], $[\mathrm{r}=-0.79, P=.001]$, and $[\mathrm{r}=-0.62, P=.019]$, respectively) in subjects with CF. Breathing reserve, $\dot{\mathrm{V}}_{\mathrm{O}_{2 \text { peak }}}(\mathrm{L} / \mathrm{min})$, and $\mathrm{AT}\left(\% \dot{\mathrm{V}}_{\mathrm{O}_{2 \text { peak }}}\right)$ were also identified as significant correlates of tau ([r $=-0.74, P=.003$, Fig. 3$],[\mathrm{r}=-0.53, P=.049$, Fig. 


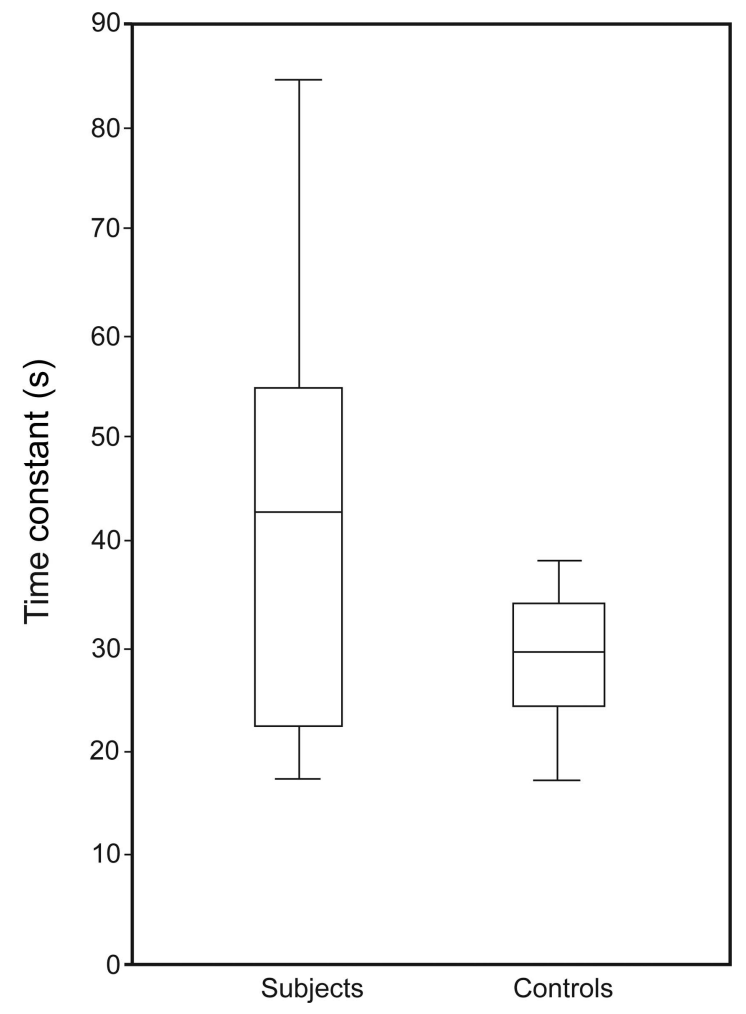

Fig. 1. Graphic representation of the time constant of the phase II response during constant workload exercise testing in adult subjects with cystic fibrosis and healthy controls. $P=.05$.

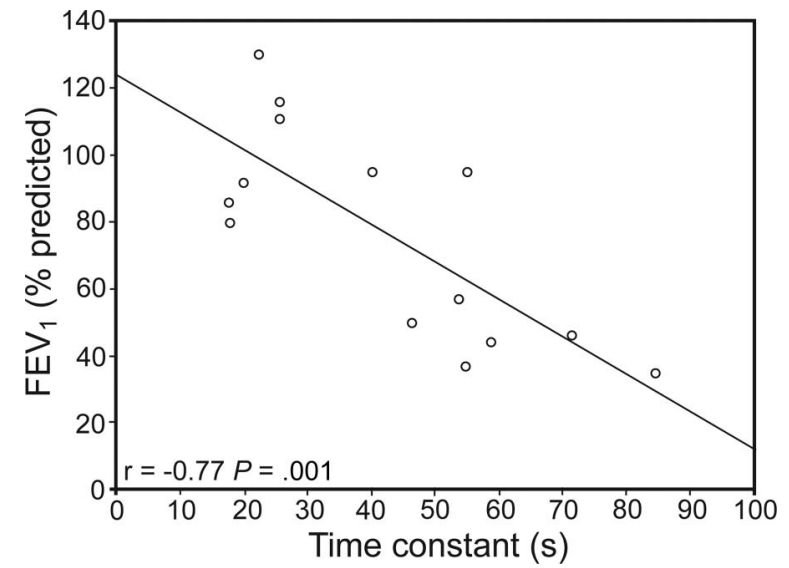

Fig. 2. Scatter graph of FEV1 (\% predicted) vs time constant in adult subjects with cystic fibrosis.

4], and [ $\mathrm{r}=-0.65, P=.013])$, respectively. $\dot{\mathrm{V}}_{\mathrm{O}_{2}} / \mathrm{t}$ slope was significantly correlated with tau $\left(\mathrm{r}=-0.58, P^{2}=.031\right)$ in the same group. A statistically significant negative correlation between tau and Schwachman score was also found ( $\mathrm{r}=-0.80, P=.001$, Fig. 5).

A univariate linear regression was performed to examine which variables were significantly correlated to tau including $\mathrm{FEV}_{1}$ (pred), $\mathrm{FVC}\left(\right.$ pred), $\mathrm{FEV}_{1} / \mathrm{FVC}, \dot{\mathrm{V}}_{\mathrm{O}_{2 \text { peak }}}$

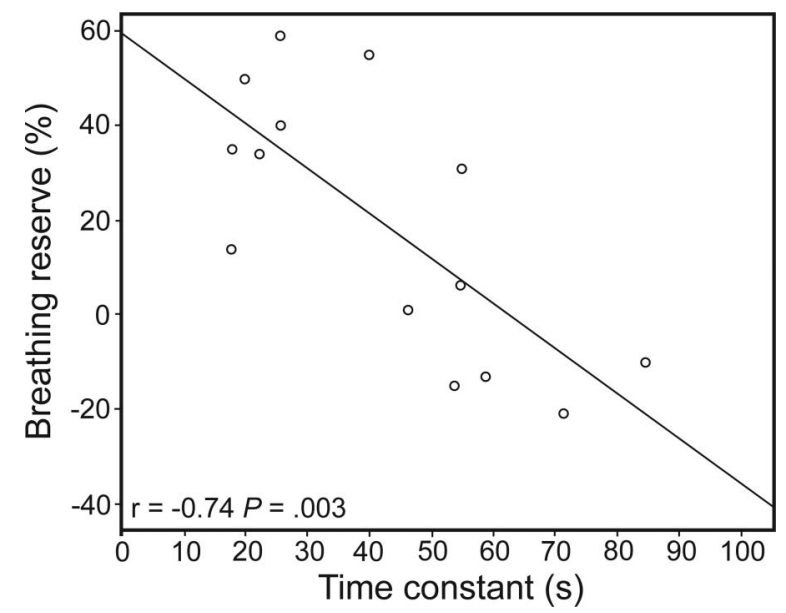

Fig. 3. Scatter graph of breathing reserve vs time constant in adult subjects with cystic fibrosis.

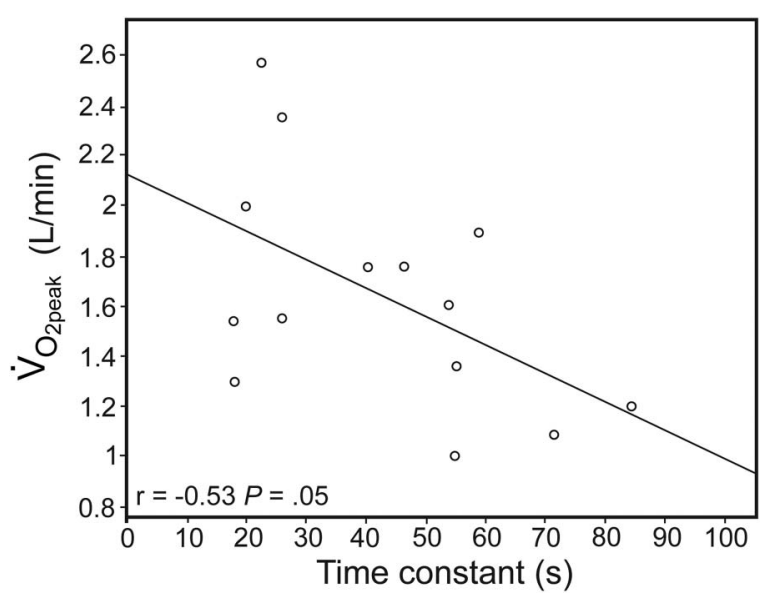

Fig. 4. Scatter graph of $\dot{\mathrm{V}}_{\mathrm{O}_{\text {2peak }}}$ vs time constant in adult subjects with cystic fibrosis.

(L/min), breathing reserve, $\dot{\mathrm{V}}_{\mathrm{E}} / \dot{\mathrm{V}}_{\mathrm{CO}_{2}}$ slope, and Schwachman score.

Multivariate linear regression analysis was conducted to determine the best linear combination of statistically significant univariate predictors for predicting tau. The results show that the Schwachman score $(\beta=-0.697$, $P=.002$ ) was the strongest independent predictor of tau $\left(\mathrm{R}^{2}=0.719, \mathrm{~F}=14.05, P=.001\right)$.

\section{Discussion}

In the present study, we have shown that CF is associated with prolonged oxygen kinetics during submaximal constant work load exercise compared to healthy subjects. This oxygen kinetics prolongation was significantly correlated with disease severity as expressed by the common prognostic markers Schwachman score, $\mathrm{FEV}_{1}$, and $\dot{\mathrm{V}}_{\mathrm{O}_{\text {2peak }}}$ in $\mathrm{CF}$. 


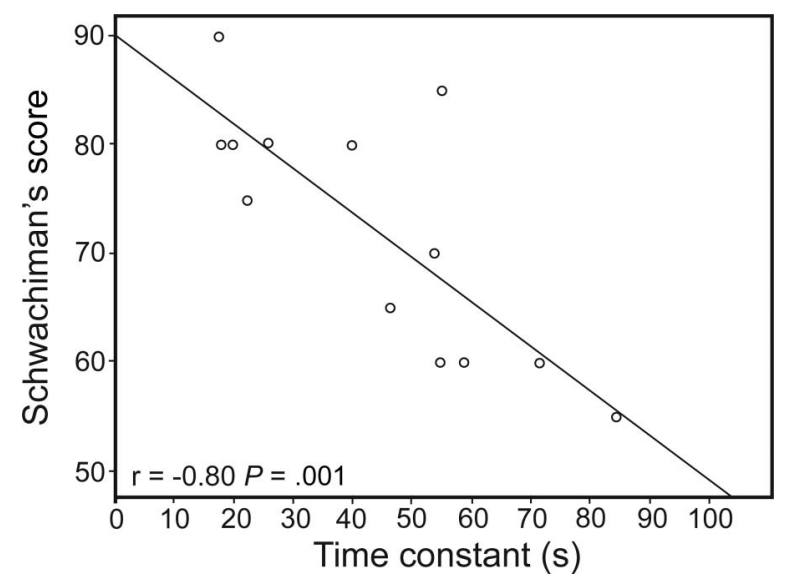

Fig. 5. Scatter graph of Schwachman score vs time constant in adult subjects with cystic fibrosis.

$\dot{\mathrm{V}}_{\mathrm{O}_{2}}$ kinetics of phase 2 of submaximal constant work load CPET have been used as an important index of central and peripheral limitation of exercise in various diseases such as COPD, ${ }^{25,26}$ heart failure, ${ }^{20}$ heart transplant recipients, ${ }^{27}$ cystic fibrosis, ${ }^{13}$ and even healthy subjects. ${ }^{28}$ The time constant of phase 2 oxygen kinetics (tau) is an index of aerobic metabolism of muscles and reflects aerobic capacity, ${ }^{21,23,29}$ but also is an index of oxygen delivery to peripheral tissues. ${ }^{26,27}$

Until now, the data for oxygen kinetics of constant work load submaximal CPET in cystic fibrosis have been very limited. Hebestreit and co-workers ${ }^{13}$ have investigated the oxygen kinetics of constant work load submaximal CPET in subjects with CF and they have demonstrated that, although there was no difference in amplitude of phase 2 $\dot{\mathrm{V}}_{\mathrm{O}_{2}}$ response between subjects with $\mathrm{CF}$ and healthy controls, the tau was prolonged. In the latter study, tau was adjusted only for oxygen desaturation and $\mathrm{FEV}_{1}$, leading to elimination of difference. Additionally, there was no documentation of the overall breathing pattern, and the $\mathrm{CF}$ population included children and adults (ages between 10 and $33 \mathrm{y}$ old), facts that generate further queries.

Our data confirm prolongation of time constant tau in subjects with CF. Furthermore, our study has shown, for the first time, correlation of tau with disease severity as it is expressed by Schwachman score, $\mathrm{FEV}_{1}$, and peak exercise capacity. The inverse correlation between tau and indices of respiratory function at rest and during exercise $\left(\mathrm{FEV}_{1}, \mathrm{FVC}, \mathrm{FEV}_{1} / \mathrm{FVC}\right.$, and breathing reserve) could indicate that phase 2 oxygen kinetics is significantly dependent on a central factor in $\mathrm{CF}$ and partly explains its prolongation by reduced oxygen delivery. This is in accordance with other studies in heart transplant recipients ${ }^{27}$ and COPD subjects. ${ }^{26}$ Most subjects with CF demonstrate an obstructive disease at spirometric evaluation. The prolonged exercise kinetics during maximal exercise has been partly explained by air trapping, ventilatory mismatch, mus- cle strength, nutritional status, and oxidative stress at the mitochondrial level. The prolongation of oxygen kinetics, which also emerged with submaximal constant work load exercise, indicates that the underlying mechanisms have early onset and probably affect overall clinical status and increase disease severity while decreasing exercise capacity. Moreover, indices of central limitation of exercise such as $\mathrm{O}_{2}$ pulse and $\dot{\mathrm{V}}_{\mathrm{E}} / \dot{\mathrm{V}}_{\mathrm{CO}_{2}}$ slope were significantly different between the 2 groups. Subjects with CF exhibit a significantly lower $\mathrm{O}_{2}$ pulse, an indirect index of stroke volume, and a significantly higher $\dot{\mathrm{V}}_{\mathrm{E}} / \dot{\mathrm{V}}_{\mathrm{CO}_{2}}$ slope, which is an index of ventilatory efficiency. These findings might indicate a reduced oxygen delivery, possibly due to some degree of pulmonary hypertension that is often present in CF, especially during exercise as has been reported elsewhere. ${ }^{30}$ However, we did not find any correlation between these indices of central limitation and phase 2 oxygen kinetics. Interestingly, cardiac function assessed by cardiac ultrasound at rest was within normal limits in our study, making this contribution to the prolonged oxygen kinetics in $\mathrm{CF}$ less possible. Moreover, although there was a slight increase in phase 1 duration in $\mathrm{CF}$, this was not statistically significant. This phase reflects the cardiodynamic phase, which is rather normal in our adult subjects with CF.

In contrast to results in the study by Hebestreit et al, ${ }^{13} \mathrm{a}$ statistically significant negative correlation was found between disease severity expressed by the Schwachman score and phase 2 oxygen kinetics. This correlation suggests that subjects with a high Schwachman score and consequently a good clinical condition demonstrate faster oxygen kinetics. To our knowledge, this is the first demonstration of a significant correlation between a clinical index of disease severity such as the Schwachman score and an index of aerobic capacity such as tau.

The inverse correlation of phase 2 oxygen kinetics with aerobic capacity $\left(\dot{\mathrm{V}}_{\mathrm{O}_{2 \text { peak }}}, \mathrm{AT}\right)$ and early recovery oxygen kinetics after maximal exercise $\left(\dot{\mathrm{V}}_{\mathrm{O}_{2}} / \mathrm{t}\right.$ slope $)$ in $\mathrm{CF}$ might also suggest that there is a peripheral factor that explains oxygen kinetics prolongation. Pouliou et $\mathrm{al}^{10}$ have previously shown that there is prolonged early recovery oxygen kinetics after maximal exercise, which might indicate an impaired oxidative muscle metabolism of subjects with CF. Possible explanatory mechanisms for low oxidative capacity and prolonged oxygen kinetics in subjects with $\mathrm{CF}$ are deconditioning, abnormalities at the mitochondrial level such as increased calcium concentration, ${ }^{31}$ lower NADH dehydrogenase activity, ${ }^{32}$ and higher $\mathrm{pH}$ optimum of NADH dehydrogenase. ${ }^{33}$ Moreover, previous data ${ }^{34}$ suggest a reduced efficiency of oxidative ATP synthesis in subjects with CF. In the literature, an association between the main $\mathrm{CF}$ gene mutation and raised energy expenditure in subjects with $\mathrm{CF}$ is reported. ${ }^{35}$ These changes probably 


\section{Slowed Oxygen Kinetics in Cystic Fibrosis}

affect muscle oxidative metabolism and may also explain phase 2 oxygen kinetics prolongation.

This study is cross-sectional, and not designed to prove causality. The study population consisted of a relative small sample size with healthy subjects not matched for age and BMI; however, the fact that, in the present study, subjects with $\mathrm{CF}$ were significantly younger than healthy subjects strengthens our findings. Younger subjects exhibit faster phase 2 oxygen kinetics. ${ }^{36}$ Subjects with CF even younger than healthy subjects exhibit slower phase 2 oxygen kinetics, outlining the role of central and peripheral factors to this phenomenon. The findings from our study are not valid for pediatric CF but only for adult CF. Moreover, the similar inspiratory capacities in both groups at baseline strengthens our data. Perpati et $\mathrm{al}^{16}$ have shown that lower baseline inspiratory capacity in subjects with $\mathrm{CF}$ correlates with poor exercise performance. The lack of echocardiographic data at the time of the study might limit our study conclusions; however, the negative medical history of cardiovascular risk factors for ischemic heart disease and a recent echocardiogram before referral at the CF out-patient clinic make cardiac involvement unlikely to explain the slow oxygen kinetics in these subjects. Definite explanatory mechanisms for prolonged oxygen kinetics during constant work load submaximal exercise cannot be deduced from the present findings; however, after thoroughly evaluating the symptom-limited CPET and its correlation with phase 2 oxygen kinetics, it seems that both central and peripheral factors influence prolonged oxygen kinetics. Further studies are needed to investigate the linking mechanisms.

\section{Clinical Implications}

These findings are clinically important, as the submaximal CPET is more tolerable and safer for debilitated subjects, who cannot perform maximal exercise. It could be used for risk stratification of subjects with CF. In the follow-up assessment, an accurate phase 2 oxygen kinetics evaluation instead of a symptom-limited CPET is suggested, avoiding the impact of low subject motivation and allowing physicians to terminate CPET considering both clinical and laboratory findings. Finally, submaximal exercise and tau estimation set the schedule of exercise training programs for subjects with $\mathrm{CF}$ and objectively assess the beneficial effects of rehabilitation.

\section{Conclusions}

Our study demonstrated that adult subjects with CF present a significant prolongation of oxygen kinetics during constant work load submaximal exercise testing in strong relation to disease severity. Both central and peripheral factors seem to be involved as explanatory mechanisms for this prolongation in subjects with $\mathrm{CF}$.

\section{REFERENCES}

1. Rohlfs EM, Zhou Z, Heim RA, Nagan N, Rosenblum LS, Flynn K, et al. Cystic fibrosis carrier testing in an ethnically diverse US population. Clin Chem 2011;57(6):841-848.

2. Cant N, Pollock N, Ford RC. CFTR structure and cystic fibrosis. Int J Biochem Cell Biol 2014;52:15-25.

3. Hewer SC, Tyrrell J. Cystic fibrosis and the transition to adult health services. Arch Dis Child 2008;93(10):817-821.

4. Sawicki GS, Dill EJ, Asher D, Sellers DE, Robinson WM. Advance care planning in adults with cystic fibrosis. J Palliat Med 2008;11(8): 1135-1141.

5. Simmonds NJ, Macneill SJ, Cullinan P, Hodson ME. Cystic fibrosis and survival to 40 years: a case-control study. Eur Respir J 2010; 36(6):1277-1283.

6. MacKenzie T, Gifford AH, Sabadosa KA, Quinton HB, Knapp EA, Goss $\mathrm{CH}$, et al. Longevity of patients with cystic fibrosis in 2000 to 2010 and beyond: survival analysis of the cystic fibrosis foundation patient registry. Ann Int Med 2014;161(4):233-241.

7. Courtney JM, Bradley J, McCaughan J, O'Connor TM, Shortt C, Bredin CP, et al. Predictors of mortality in adults with cystic fibrosis. Pediatr Pulmonol 2007;42(6):525-532.

8. Urquhart DS. Exercise testing in cystic fibrosis: why (and how)? J R Soc Med 104 Suppl 1:S6-14, 2011.

9. Shwachman H, Kulczycki LL. Long-term study of one hundred five patients with cystic fibrosis; studies made over a five- to fourteenyear period. J Dis Child 1958;96(1):6-15.

10. Pouliou E, Nanas S, Papamichalopoulos A, Kyprianou T, Perpati G, Mavrou I, Roussos. Prolonged oxygen kinetics during early recovery from maximal exercise in adult patients with cystic fibrosis. Chest 2001;119(4):1073-1078.

11. Pastre J, Prevotat A, Tardif C, Langlois C, Duhamel A, Wallaert B. Determinants of exercise capacity in cystic fibrosis patients with mild-to-moderate lung disease. BMC Pulm Med 2014;14:74.

12. Almajed A, Lands LC. The evolution of exercise capacity and its limiting factors in cystic fibrosis. Paediatr Respir Rev 2012;13(4): 195-199.

13. Hebestreit H, Hebestreit A, Trusen A, Hughson RL. Oxygen uptake kinetics are slowed in cystic fibrosis. Med Sci Sports Exerc 2005; 37(1):10-17.

14. Miller MR, Hankinson J, Brusasco V, Burgos F, Casaburi R, Coates A, et al. Standardisation of spirometry. Eur Respir J 2005;26(2):319338.

15. Papazachou O, Anastasiou-Nana M, Sakellariou D, Tassiou A, Dimopoulos S, Venetsanakos J, et al. Pulmonary function at peak exercise in patients with chronic heart failure. Int J Cardiol 2007; 118(1):28-35

16. Perpati G, Nanas S, Pouliou E, Dionyssopoulou V, Stefanatou E, Armeniakou E, et al. Resting respiratory variables and exercise capacity in adult patients with cystic fibrosis. Respir Med 2010;104(10): 1444-1449.

17. Hansen JE, Sue DY, Wasserman K. Predicted values for clinical exercise testing. Am J Respir Dis 129(2 Pt 2):S49-55, 1984.

18. Beaver WL, Wasserman K, Whipp BJ. A new method for detecting anaerobic threshold by gas exchange. J Appl Physiol 1986;60(6): 2020-2027.

19. Nanas S, Nanas J, Kassiotis C, Alexopoulos G, Samakovli A, Kanakakis J, et al. Respiratory muscles performance is related to oxygen kinetics during maximal exercise and early recovery in patients with congestive heart failure. Circulation 1999;100(5): 503-508. 


\section{Slowed Oxygen Kinetics in Cystic Fibrosis}

20. Roditis P, Dimopoulos S, Sakellariou D, Sarafoglou S, Kaldara E, Venetsanakos J, et al. The effects of exercise training on the kinetics of oxygen uptake in patients with chronic heart failure. Eur J Cardiovasc Prev Rehab 2007;14(2):304-311.

21. Vasileiadis I, Roditis P, Dimopoulos S, Ladis V, Pangalis G, Aessopos A, et al. Impaired oxygen kinetics in beta-thalassaemia major patients. Acta Physiol 2009;196(3):357-363.

22. Lamarra N, Whipp BJ, Ward SA, Wasserman K. Effect of interbreath fluctuations on characterizing exercise gas exchange kinetics. J Appl Physiol 1987;62(5):2003-2012.

23. Whipp BJ, Rossiter HB, Ward SA. Exertional oxygen uptake kinetics: a stamen of stamina? Biochem Soc Trans 2002;30(2): 237-247.

24. Whipp BJ, Ward SA, Lamarra N, Davis JA, Wasserman K. Parameters of ventilatory and gas exchange dynamics during exercise. J Appl Physiol 1982;52(6):1506-1513.

25. Somfay A, Pórszász J, Lee SM, Casaburi R. Effect of hyperoxia on gas exchange and lactate kinetics following exercise onset in nonhypoxemic COPD patients. Chest 2002;121(2):393-400.

26. Chiappa GR, Borghi-Silva A, Ferreira LF, Carrascosa C, Oliveira $\mathrm{CC}$, Maia J, et al. Kinetics of muscle deoxygenation are accelerated at the onset of heavy-intensity exercise in patients with COPD: relationship to central cardiovascular dynamics. J Appl Physiol 2008; 104(5):1341-1350.

27. Mettauer B, Zhao QM, Epailly E, Charloux A, Lampert E, HeitzNaegelen B, et al. $\operatorname{VO}(2)$ kinetics reveal a central limitation at the onset of subthreshold exercise in heart transplant recipients. J Appl Physiol 2000;88(4):1228-1238.

28. Fukuoka Y, Grassi B, Conti M, Guiducci D, Sutti M, Marconi C, et al. Early effects of exercise training on on- and off-kinetics in 50-year-old subjects. Pflugers Arch Eur J Physiol 2002:443(5-6):690-697.

29. Grassi B. Skeletal muscle VO2 on-kinetics: set by O2 delivery or by $\mathrm{O} 2$ utilization? New insights into an old issue. Med Sci Sports Exercise 2000;32(1):108-116

30. Manika K, Pitsiou GG, Boutou AK, Tsaoussis V, Chavouzis N, Antoniou $\mathrm{M}$, et al. The impact of pulmonary arterial pressure on exercise capacity in mild-to-moderate cystic fibrosis: a case control study. Pulm Med 2012;252345, 2012.

31. Shapiro BL. Evidence for a mitochondrial lesion in cystic fibrosis. Life Sci 1989;44(19):1327-1334.

32. Valdivieso AG, Santa-Coloma TA. CFTR activity and mitochondrial function. Redox Biol 2013;1(1):190-202.

33. Shapiro BL, Feigal RJ, Lam LF. Mitrochondrial NADH dehydrogenase in cystic fibrosis. Proc Natl Acad Sci USA 1979;76(6):29792983.

34. de Meer K, Jeneson JA, Gulmans VA, van der Laag J, Berger R. Efficiency of oxidative work performance of skeletal muscle in patients with cystic fibrosis. Thorax 1995;50(9):980-983.

35. O'Rawe A, Dodge JA, Redmond AO, McIntosh J, Brock DJ. Gene/ energy interaction in cystic fibrosis. Lancet 1990;335(8688):552553.

36. Xu F, Rhodes EC. Oxygen uptake kinetics during exercise. Sports Med 1999;27(5):313-327. evel2 